\title{
DOMUS AUREA: VIVIR COMO SERES HUMANOS
}

Carlos J. Mc Cadden M.*

\section{El profesor Carlos de la Isla siempre} defendió que la educación universitaria ha de ser universal, crítica y libre. La universidad es ciertamente el sitio más adecuado para adquirir una gran cantidad de conocimientos sobre un gran número de temas. Mas esta diversidad de conocimientos debe integrarse en un saber ordenado y ordenador, capaz de trazar caminos a los seres humanos; aclarar el sentido de las ciencias y de la conducta humana y conocer sus causas, particularmente las últimas — como dice Aristóteles - , para participar de las características de la sabiduría y del sabio. Es necesario entender - dice David Hume - que todas las ciencias se relacionan en mayor o menor grado con el ser humano, pues, aunque algunas parezcan desenvolverse a gran distancia, siempre regresan finalmente, por una u otra vía, al hombre.

Tal es una auténtica educación que no consiste simplemente en acrecentar conocimientos, sino en desarrollar a los seres humanos que participan en ella. Es la formación digna del hombre libre, por la que se busca y se cultiva la sabiduría, puntal sobre el que se cultivan las ciencias y las técnicas destinadas al lucro o al placer. La educación es liberal porque libera de la esclavitud de los exclusivos intereses utilitarios; es humanista en cuanto forma la humanitas, forja al Homo humanus, mediante la incorporación de la $\pi \alpha 1 \delta \varepsilon i ́ \alpha$ griega. La actualidad de este ideal

* Jefe del Departamento Académico de Estudios Generales, ITAM. 
educativo es confirmada por la Magna Charta, Declaración del Parlamento Universal de la Juventud de la UNESCO de agosto de 2014, que dice: "Deseamos formar una nueva civilización de personas que aspiren a tener una vida plena y con un sentido transcendente, que vivan valores y virtudes que dignifican al ser humano. Queremos contribuir a reavivar la esperanza en nuestra sociedad para que se haga posible un mundo fraterno."

El humanismo del profesor De la Isla nos propone hacernos conscientes de nuestra vocación como seres humanos y encontrar el sentido de la vida, el cual es descubierto por la inteligencia y ansiado por la voluntad, con el propósito de recrear una cultura universitaria y una civilización global unida, que apele, atraiga y reúna bajo su estandarte a todos los pueblos del mundo. Esta manera de entender al Homo humanus integra en el tiempo lo nuevo y lo antiguo (nova et vetera) y en el espacio lo cercano y lo remoto en una reflexión que avanza hacia una cultura universitaria universal. Esto resulta ser muy diferente de lo que se pretende inculcar hoy en algunas universidades con la multidisciplinariedad, entendida como una mezcla no integradora de varias disciplinas en la que cada una conserva sus métodos y suposiciones; la interdisciplinariedad, que es el trabajo científico que cruza los límites tradicionales y requiere metodológicamente la colaboración de diversas y diferentes disciplinas por el surgimiento de nuevas necesidades; el multiculturalismo, que se conforma con retratar y relacionar la diversidad cultural en el plano local, nacional y regional; el interculturalismo, que exige una descolonización intelectual de una concepción extremadamente monocultural y eurocentrista, y la pluriversidad que cuestiona su misma denominación —universitas, de unum (uno) y vertere (girar; convertir) para dejar lo 'uno' por lo 'pluri' resolviendo el debate uni/pluriversidad a favor del "constante movimiento" en torno a una pluralidad de puntos nodales: cada cultura, cada ciencia, cada élite intelectual, cada modelo teórico, etc. Sería una "interversidad" que sobrepasa el monoculturalismo académico y afirma una racionalidad múltiple. Estos nuevos esfuerzos científicos que generan un área de integración fantástica podrían ser estudiados como materias optativas, porque son trascendentes tentativas de síntesis en una atmósfera cognoscitiva regida por lo analítico. 
Sin embargo, ubicar áreas de integración de saberes no es lo mismo que contribuir a la formación integral de la persona humana y al desarrollo de una sociedad más libre, más justa y más próspera, tal como lo propone la misión del ITAM. Resultan siempre bienvenidos estos cuestionamientos deconstructivos de la universitas, mientras no se pierda de vista que en el fondo de lo que se trata es de formar la humanitas en el hombre, porque todo saber finalmente depende y se relaciona con el hombre.

Carlos de la Isla nos previene contra la especialización excesiva y deshumanizante en la universidad, que termina por eliminar no solo los denominadores comunes de la cultura, por los cuales, según nos dice Mario Vargas Llosa, los seres humanos logran coexistir. Esa especialización, como el árbol que impide ver el bosque, pretende encubrir la posición central que ha de tener la comprensión de la dignidad de la persona humana dentro del conjunto de saberes. La educación universitaria debe mostrar el vínculo fraterno entre los seres humanos, obligándolos a dialogar y a ser conscientes del fondo espiritual común que trasciende la especialidad.

Para el maestro De la Isla, el ITAM siempre ha sido una comunidad en un sentido pleno, en cuyo fondo está el ser humano y su dignidad. Ha sostenido continuamente que nuestro Instituto materializa la esencia de la universidad, lugar privilegiado para la comunicación y circulación del pensamiento, mediante el trato personal, tal como lo afirmaba John Henry Newman. Es un lugar en el que el entendimiento puede desplegarse y especular, seguro de que encontrará adversarios y jueces en el tribunal de la verdad, en el cual el error se manifiesta mediante el diálogo entre entendimiento y entendimiento, el conocimiento y el conocimiento del otro.

La verdadera vida es la vida descubierta, esclarecida y entendida, decía Proust. Solo así se puede lograr vivir plenamente, a diferencia de la vida artificial que no ha sido pensada por nosotros mismos sino por otros. Esto mismo sucede con la vida intelectual, que puede ser auténtica o enajenada y espuria. En esta última no se ejerce la libertad, sino una falsificación de ella, plagada de dogmatismos que no admiten cuestionamientos. La cultura humana es un tesoro que debe ser apropiado; y si 
bien comenzó a existir por obra de cada individuo que contribuyó a crearla, invariablemente lo ha sido dentro del contexto de la comunidad que lo fecundó. A su vez, es la misma comunidad la que realmente la recibe, pues la cultura solamente existe cuando es incorporada por otros y pasa a formar parte de la vida social de uno o varios países que la viven como experiencia compartida. En el ITAM, el Departamento de Estudios Generales se entiende como la entidad académica más propiamente orientada a formar en la persona un tipo de cualidad que le permita su desarrollo integral y la capacite para ubicarse significativa y responsablemente en el mundo a partir de una trayectoria histórica. Este Departamento debe proveer la cultura universitaria esencial sobre la que deben desarrollarse sanamente las disciplinas particulares elegidas.

De una manera particular y comprensiva, el doctor Carlos de la Isla siempre ha sostenido que, dentro del Departamento de Estudios Generales, la lectura directa de los grandes autores y el estudio de los grandes problemas de la civilización contemporánea posee un papel fundamental. Esta tarea debe tener como guía el carácter permanente de las verdaderas preocupaciones humanas en las distintas épocas de la humanidad, para así guardar lealtad a México, a sus valores y a sus tradiciones, y darle a nuestro patrimonio colectivo un sentido local, nacional y mundial.

Para él, los cursos de Ideas e Instituciones Políticas y Sociales y los de Problemas de la Civilización Contemporánea tienen una importancia primordial para la formación que se proponen las universidades, pues los estudiantes deben conocer sus problemas y comprometerse en la construcción de un mundo mejor. Son cursos destinados a quienes aman la vida, a quienes procuran conquistar la justicia, la paz, la libertad y que por ello odian la guerra, la violencia y la adoración del dinero hasta el desprecio de las personas. Estos cursos no se resuelven en un círculo interminable de tragedias, sino que proponen conocer los conflictos en toda su realidad. Maestros y alumnos deben realizar un análisis crítico y juzgar sobre la naturaleza, causas y complejidad de los mismos, con el fin de descubrir, construir, imaginar y proponer soluciones. Crear utopías que denuncien y anuncien, pero también aquellas de ideales tan altos que, aunque inalcanzables, ayuden a elevar moralmente a los estu- 
diantes. El doctor De la Isla ha pensado permanentemente que de los problemas transitamos de manera continua a las ideas y de las ideas a los problemas de la vida, dando así vida a las ideas. Por eso, los cursos de Ideas y Problemas se complementan. Desde las ideas, los problemas adquieren otras dimensiones; se conocen mejor, se aprecian mejor las angustias, urgencias y oscuridades de los más graves problemas de nuestra civilización y de ahí se transita de las ideas a la vida, siempre auxiliados por esa gran maestra que es la Historia. En los cursos de Historia Sociopolítica de México y de Problemas de la Realidad Mexicana Contemporánea el estudiante puede emplear las ideas y los problemas estudiados para construir nuevas fórmulas. No obstante, para Carlos de la Isla, el curso de Problemas de la Realidad Mexicana Contemporánea es fundamental en todas las carreras, si hemos de tomar en serio el gran objetivo institucional de colaborar en la construcción de "una sociedad más libre, más justa, más humana", como lo establece la misión del ITAM.

El doctor De la Isla advierte incansablemente del peligro de formar alumnos sin conciencia social, porque se convierten en individuos que eventualmente serán incapaces de empatía. El espejo del bestial Narciso reflejará su personalidad egoísta y ocultará su parte más abominable, la que niega al "otro" y solo le permite "verse" a sí mismo, imaginando que el "otro" no es sino en función de sí mismo.

Para el maestro Carlos de la Isla cada individuo debe aspirar auténticamente a "ser-a-través-de-otros", y reconquistar su propia sociabilidad para poder ser auténticamente él mismo. Y nos recuerda que el egoísta no tiene un auténtico amor de sí mismo, entre otras cosas porque desconoce y desprecia en sí mismo su naturaleza social. Para él, de ser verdadera la norma que exige la maximización de los beneficios individuales, habría que darle su verdadero sentido y ponerla al servicio de los demás. Nada tiene de malo amarse uno mismo y de esa misma manera a los demás. La antropología del doctor De la Isla no está centrada en la formación de capital, sino en la riqueza que encuentra su fundamento en el trabajo. Pero el trabajo sería penoso sin el apoyo de los demás. El mercado finalmente supone esta experiencia, esto es, el que cada persona pueda intercambiar los productos de trabajo y así satisfacer sus necesidades por 
medio de su trabajo y las de los demás. Adam Smith decía que la división del trabajo y su especialización es la riqueza de una nación. Trabajamos con los otros y para los otros. El trabajo humano solo adquiere su sentido original y su justo valor cuando se coloca frente a los demás y permite la satisfacción de las necesidades de todos.

El doctor De la Isla ha sido invariablemente un "disruptor" del sistema y del establishment. Por medio de la materia optativa que infatigablemente impartía cada semestre, denominada Ética, Sociedad y Empresa, la cual le parecía imprescindible en una escuela de administración y de economía, constantemente buscó introducir un nuevo orden que advierta de la necesidad de la ética en la esfera empresarial, pues hay organizaciones que ignoran en la práctica sus mandatos y se conducen exclusivamente de acuerdo con la norma de maximizar sus beneficios a toda costa y sin límites. Sin duda, esta manera de administrar tiene un enfoque riesgoso para la empresa. Una corporación sin ética puede convertirse en una amenaza para quienes trabajan en ella y para el bien común, a la vez que puede verse envuelta en escándalos de corrupción, discriminación laboral o daño al medio ambiente. En algunos casos, probablemente con mayor perversidad, la ética se invoca y se utiliza como mecanismo de control sobre los empleados de menor rango en la organización cuando ella misma no actúa conforme a las normas y principios que predica. El profesor De la Isla ha afirmado persistentemente que el sentido ético en la empresa no significa la renuncia a las ganancias lícitas ni la disolución de su naturaleza lucrativa, pero sí que estas tengan como límite la dignidad de las personas.

En cierto sentido, todo ser humano sostiene una carga y el conjunto de los seres humanos comparten su peso, son naturalmente solidarios y fundamentalmente abiertos a la benevolencia. Saben del ser del otro, actúan en consecuencia y requieren a los demás para aligerar el peso de su existencia. El que cada quien procure tan solo su beneficio es de alguna manera negar la existencia de los demás y pretender no necesitarlos. Esa es la definición de la máxima perversión social y el origen de la violencia. El quimérico ideal del self-made man que pretende haber llegado por sus propios esfuerzos a su actual nivel de riqueza o a su 
posición (social), se miente a sí mismo cuando piensa no deberle nada a nadie. Esto es no querer ver que no podría ni siquiera hablar, pues la palabra $(\lambda \circ \gamma \circ \varsigma)$ y el lenguaje son, al igual que él mismo, un fruto de la sociedad. Dos o más narcisistas juntos que interactúan, generan violencia y no agresión. La agresión legítima es la parte agreste, rústica, del ser humano que le permite cosechar, en latín legere (leer), mientras que la violencia es un ariete, una máquina que rompe y destruye la libertad y la productividad del otro. En un mundo así no hay espacio para el obrar ajeno; el otro no debe producir y si produce, es menester destruir violentamente su fruto. Esto sería la competencia desmedida y no la competencia sana que saca lo mejor de los demás en vez de destruirlos o sacarlos del mercado, particularmente cuando se trata de dejarlos en el desempleo.

Todos los integrantes de la comunidad universitaria tenemos mucho que aprender del maestro Carlos de la Isla, quien nos ofrece, entre otras cosas, una concepción de la universidad como "conciencia crítica de la sociedad", que posee el atributo invariable del "pensar" en sus múltiples modalidades: meditar, dudar, analizar, razonar... En esto retoma a los grandes pensadores y nos invita a ser conscientes de que "la universidad es la comunidad de estudiantes y profesores que se reúnen para pensar", como dice el Cardenal Newman. Recuerda a Jean-Paul Sartre: "La universidad está hecha para hombres capaces de dudar"; a Robert Hutchins: "La universidad es el espacio recogido para meditar los problemas intelectuales del Mundo"; y a Karl Jaspers: "La universidad es el recinto sagrado de la razón". Por otro lado, su noción de la labor del maestro como partero de almas, que recuerda a José Vasconcelos y encuentra su origen en la visión que tenía Sócrates de sí mismo. Él tiene muy claro lo que hacemos los profesores de Estudios Generales,

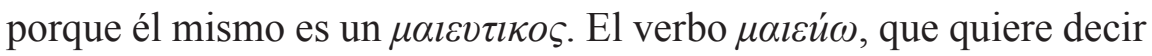
en griego "partear", tiene que ver con el ser partero. Un mayeuticós es un perito en partos, y en la universidad, un perito en el parto de las almas. El maestro de Estudios Generales debe ser un perito en el alumbramiento de las ideas de nuestros alumnos, porque solo si los alumnos dan a luz sus propias ideas, las van a defender como propias a lo largo de 
su vida. El discente no solamente acrecienta su conocimiento por la mera recepción pasiva de ideas hasta entonces desconocidas, sino que es inseminado por ellas y su actividad frente a estas lo ilumina y lo forma. Es la acción del poder formativo la que le da un nuevo orden y significado al material entonces adquirido. Es la actividad fecundante de lo nuevo la que preña al pensamiento e inmediatamente este concibe algo nuevo haciendo suyos los objetos hasta entonces ignorados. Es así como el conocimiento se amplía, se ilumina, pero sobre todo, se forma. Los estudiantes comparan ideas, las sistematizan, les asignan su verdadero lugar, entienden su valor y determinan su dependencia mutua. Así descubren que su vida depende de sus ideas; y esas ideas que procrearon serán por ellos mismos encarecidamente custodiadas y nutridas. "Somos nuestras ideas", decía Ortega y Gasset. Esta es la diferencia entre vivir y ser vivido; "ser vivido no es vivir", nos dice Carlos de la Isla, repitiendo a Unamuno. Ese es el hombre que sabe, que sabe de sí y piensa mientras sabe, por ello sus enseñanzas son una constante invitación no solo a vivir sino a vivir bien.

Para el doctor Carlos de la Isla Veraza, el Instituto Tecnológico Autónomo de México, y en particular el Departamento Académico de Estudios Generales, fue y es una casa dorada, domus aurea. 